\title{
Bus ridership and its determinants in Beijing: A spatial econometric perspective
}

\author{
Jiaoe Wang ${ }^{1,2} \cdot$ Yanan $\mathrm{Li}^{3} \cdot$ Jingjuan $\mathrm{Jiao}^{3}$ (D) $\cdot$ Haitao $\mathrm{Jin}^{4} \cdot$ Fangye $\mathrm{Du}^{1,2}$
}

Accepted: 17 November 2021 / Published online: 5 January 2022

(c) The Author(s) 2022

\begin{abstract}
Understanding the temporal and spatial dynamics and determinants of public transport ridership play an important role in urban planning. Previous studies have focused on exploring the determinants at the station level using global models, or a local model, geographically weighted regression (GWR), which cannot reveal spatial autocorrelation at the global level. This study explores the factors affecting bus ridership considering spatial autocorrelation using the spatial Durbin model (SDM). Taking the community in Beijing as the basic study unit, this study aims to explore the temporal and spatial dynamics of bus ridership and identify its key determinants considering neighboring effects. The results show the following: (1) The temporal dynamics are quite distinct on weekdays and weekends as well as at different time slots of the day. (2) The spatial patterns of bus ridership varied across different time slots, and the hot areas are mainly located near the central business district (CBD), transport hubs, and residential areas. (3) Key determinants of bus ridership varied across weekends and weekdays and varied at different time slots per day. (4) The spatial neighboring effects had been verified. This study provides a common analytical framework for analyzing the spatiotemporal dynamics and determinants of bus ridership at the community level.
\end{abstract}

Keywords Bus ridership - Spatiotemporal dynamics - Factor analysis $\cdot$ Spatial economics model

Jingjuan Jiao

jjjiao@bjtu.edu.cn

1 Key Laboratory of Regional Sustainable Development Modeling, Institute of Geographic Sciences and Natural Resources Research, Chinese Academy of Sciences, Beijing, China

2 College of Resources and Environment, University of Chinese Academy of Sciences, Beijing, China

3 School of Economics and Management, Beijing Jiaotong University, Beijing, China

4 School of Computer, Beijing Information Science and Technology University, Beijing, China 


\section{Introduction}

With increasing urbanization, the ownership of private cars has rapidly increased in recent decades, generating many social and economic problems, such as traffic congestion, environmental pollution, and traffic noise (Gruyter et al. 2020). Public transport, including urban rail transit and bus systems, is widely considered as useful tool to decrease private car usage. Understanding the key determinants of public transport ridership might be of great practical significance for addressing transport congestion, transport demand estimation and planning, and urban planning.

Previous studies have explored the determinants of public transit ridership at both the macro and micro levels in recent decades. At the macro level, existing studies have mainly focused on comparing the determinants of ridership across different cities using aggregate data (Taylor et al. 2009; Currie and Delbosc 2011; Rahman and Balijepalli 2016; Ingvardson and Nielsen 2018). At the micro-level, bus ridership at the station or station-to-station level is commonly set as the dependent variable, and the contributing factors within the catchment areas of stations are set as the independent variables (Kuby et al. 2004; Chakour and Eluru 2016). Commonly, the catchment area of stations is set as a circle with a fixed radius or path distance, such as $500 \mathrm{~m}$ (Li et al. 2016), $600 \mathrm{~m}$ (An et al. 2019), $400 \mathrm{~m}$, and $800 \mathrm{~m}$ (Zhao et al. 2013). The differentiated radius of the catchment area determines to what extent contributing factors will drive the effects. To eliminate the influence of the radius of the catchment area, some scholars have tried to set different sizes of buffer zones, including $200 \mathrm{~m}, 400 \mathrm{~m}, 600 \mathrm{~m}, 800 \mathrm{~m}$, and $1000 \mathrm{~m}$ (Chakour and Eluru 2016) or $300 \mathrm{~m}$, $600 \mathrm{~m}$, and $900 \mathrm{~m}$ (Jun et al. 2015). Commonly, the catchment area of stations is not continuous in space, which means that the contributing factors within the catchment area cannot reflect all the characteristics of persons and cities. Thus, it is necessary to explore the relationship between public transit ridership and its determinants in a continuous region, i.e., townships or communities, which is a mass self-government organization to implement self-management, self-service, and self-monitoring in China.

The determinants of bus ridership established in previous studies included internal strategies (e.g., the scale, density, and accessibility of public transport), alternative transport connections (e.g., parks and private cars), and external forces (e.g. socioeconomic characteristics, land use, and the built environment). Amongst them, public transport characteristics are considered to be very important to attract riders and are commonly evaluated from the price, scale, density, coverage, and accessibility perspectives using the number of bus and subway stations, road/bus/subway route length, and travel distance to the nearest stations (Chiou et al. 2015). Moreover, the connectivity of a transport network, reflecting how well a place is located in the transport network, has been introduced in some studies (Ingvardson and Nielsen 2018; He et al. 2019). The alternative transport connections are commonly explored using car ownership (Rahman and Balijepalli 2016) and road network density (Zhao et al. 2013; Jun et al. 2015).

The external factors refer to the socio-economic attributes and built environment. Socioeconomic characteristics are traditionally evaluated using population, employment, and revenue or income (Zhao et al. 2013; Zhu et al. 2018; He et al. 2019), which have been verified to have a positive influence on public ridership in many studies. The proportion of different types of land status, such as residential areas, commercial areas, industrial areas, and mixed land use, are most widely employed as land use or built environment variables (Li et al. 2016). However, in most cities, data on the proportion of different types of land status are unavailable. Some researchers have used the number of retailers, schools, banks, 
hospitals, hotels, and restaurants to explore the built environment characteristics (He et al. 2019). Additionally, some researchers have studied the impacts on ridership of the built environment from three dimensions: density, diversity, and design (Cervero and Kockelman 1997).

Regarding the methodology, global models, including multiple linear regression analysis with ordinary least squares (OLS) (Chow et al. 2006; Messenger and Ewing, 2007), poisson regression models (Kuby et al. 2004; Chu 2004), simultaneous regressions (Taylor et al. 2009), structural equation models (Sohn and Shim 2010), aggregate logit models (Buehler 2011; Taylor and Fink 2013) and tobit regression models (Boame 2004; Chiou et al. 2015), are widely used to explore the determinants of public transport ridership. However, most of these models are formulated under different hypotheses and cannot reveal the neighboring effects and spatial autocorrelation, which means that the bus ridership of a region might also be influenced by the attribution of its neighbors. Recently, a local model, namely, geographically weighted regression (GWR) and the semi-parametric geographically-weighted regression (SGWR) have been introduced to explore spatial autocorrelation and neighboring effects (Gutiérrez et al. 2011; Chen et al. 2019; Kuai and Wang 2020). This approach could be used to address spatial autocorrelation and spatial nonstationarity at the local level but not at the global level and cannot differentiate the influence of its factors and those of its neighbors. To address these limitations, this study introduces a global spatial econometric model that incorporates spatial autocorrelation or neighborhood effects at the global level (Elhorst 2010).

Except for spatial nonstationarity, several studies began to focus on the temporal nonstationarity of rail station ridership by comparing the determinants of public transport ridership on weekdays and weekends and at peak and off-peak hours considering the temporal variation of ridership (Zhu et al. 2018; Chen et al. 2019). Most of these studies concentrated on urban rail transit instead of bus transport. Although there might be some similarities in trends between urban rail transit and bus ridership, i.e., the existence of peak and off-peak hours, some differences also exist, i.e., the start time and duration of peak and off-peak hours and the spatial patterns of ridership. Given that it is a major public transport mode, it is necessary to explore the determinants of bus ridership.

Therefore, this study introduces a global spatial econometric model to explore the temporal and spatial dynamics of bus ridership and identify its key determinants considering neighboring effects by taking communities in Beijing as the basic unit. First, station-level smart card data are transformed and assigned in each community using the inverse distance weight (IDW) considering that the demand for persons might decrease with an increase in the distance to bus stations. Second, three spatial econometric models, including the spatial lag model (SLM), spatial error model (SEM), and spatial Durbin model (SDM), are introduced to analyze the determinants of bus ridership considering spatial autocorrelation at the global level. Third, the temporal and spatial dynamics of bus ridership within the SixRing Road of Beijing are explored to detect the hot areas and peak hours of bus ridership. Finally, the determinants of bus ridership are identified and compared by considering ridership on weekends and weekdays and during morning peak hours, afternoon peak hours, daytime off-peak hours, and night-time off-peak hours.

This article is organized as follows. Section 2 reviews and analyses the literature related to the determinants of public transport ridership at the micro-level. Section 3 focuses on the research methods and data collection. Section 4 explores the temporal and spatial dynamics of bus ridership. Section 5 analyses the regression results. Section 6 presents the conclusions and discussions. 


\section{Methodology and data}

\section{Data collection and description}

Beijing, as a populous megacity, has a population size of 21.7 million, inducing enormous travel demand. In 2018, the total number of weekday bus riders in the urban areas of Beijing was 6.3 million, accounting for $16.06 \%$ of the total number of weekday trips. Geographically, bus ridership is mainly distributed in the central urban areas of Beijing, especially within the Six-Ring Road, where there were 3616 bus stations in 2015. The smart card data (SCD) for a single week of 2015 were obtained from the Beijing Transportation Information Center, and they account for $85 \%$ of the total trips in the system (Zhong et al. 2016). The SCD is widely used to explore the commute mode preference (Wang et al. 2020), the transit-based health seeking patterns (Du et al. 2020), and the Jobworker dynamics (Huang et al. 2019). These data include information on the boarding station, alighting station, boarding time, alighting time, and many other items of all bus riders. Since there might be several bus stations at the crossroads, and these stations might serve the same residents in the nearby community, so we adopt community as the basic unit for analysis in this paper. For example, at the crossroad of Beitucheng West Road and Huayuan East Road, there are four bus stations, named Mudanyuan East, Mudanyuan West, Mudanyuan South, and Mudanyuan North stations, located at the different directions of the crossroad. To better understand the spatial patterns and the influential factors of bus riders, the OD-linked transit trips are aggregated to a certain spatial area (community level).

A community, one kind of continuous area in cities, is a mass self-government organization under the leadership of community residents to implement self-management, selfservice, and self-monitoring. In China, most transport services are distributed by taking the community as the smallest unit. Thus, the 3049 communities located within the Six-Ring Road of Beijing are chosen as the objects of study in this study, as shown in Fig. 1. The travel demand of communities is calculated according to the bus ridership at the station level. Considering that the demand for persons might decrease with an increase in the distance to bus stations, the inverse distance weight (IDW) method is introduced to transfer the bus ridership at each bus station to that in each community in this study. The formulas for the IDW are written as:

$$
\text { IDW }: z_{u}=\frac{\sum_{i=1}^{s} z_{i} d_{\mathrm{iu}}^{-2}}{\sum_{i=1}^{s} d_{\mathrm{iu}}^{-2}}
$$

where $z_{i}$ are the observed data points noted as $i$ and $d_{\mathrm{iu}}$ is the distance from observed data $i$ to pixel $u$. The bandwidth used in the IDW is set as $500 \mathrm{~m}$, which is the access distance for walking.

To better understand the temporal nonstationarity of bus ridership determinants, the average bus alighting ridership per day in a week, on weekdays, and weekends is chosen as the dependent variable to explore the determinants across a week. The average bus alighting ridership per hour during morning peak hours, afternoon peak hours, daytime off-peak hours, and night-time off-peak hours is chosen as the dependent variable to explore the determinants across the course of a day. According to the temporal dynamics of bus ridership (refer to Sect. 3.1), the morning peak, evening peak, daytime off-peak, and night-time off-peak hours are respectively set as 6:30 -10:00, 16:30 -20:00, 10:00 -16:30, and 20:00 $-6: 30$. 


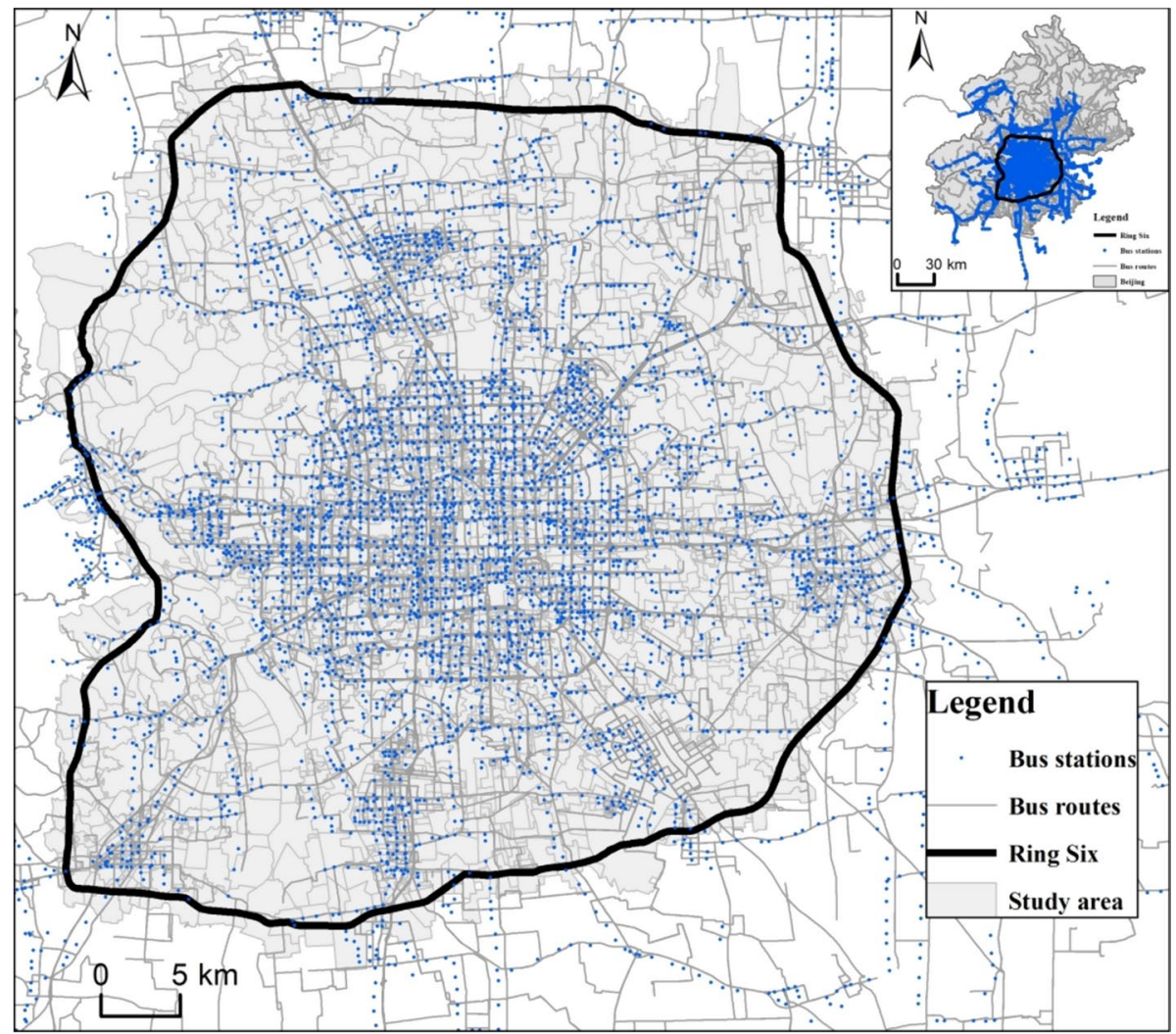

Fig. 1 Study areas and bus network in Beijing (2015)

According to previous studies (Kuby et al. 2004; Chakour and Eluru 2016; Zhu et al. 2018; Chiou et al. 2015), the independent variables in this study include the transport endowment indicators, socio-economic attributes, and built environment attributes of each community.

The transport endowment of a community reflects how well a community is positioned in the transport network, which refers to the indicators related to the bus infrastructure and service network of the bus network, its alternative transport modes, and the intercity transport location endowment. The transport endowment related to the bus network includes the indicators reflecting its scale, accessibility, and connectivity characteristics, which includes the density of bus stations (bus stations), the distance to the nearest bus stations (Dist_to_bus stations), and the betweenness centrality in the bus service network (Betw_bus). The alternative transport indicators include the density of subway stations (subway stations), the shortest distance to the subway stations (Dist_ to_subway stations), the density of the road network (Road density), and the betweenness centrality in the road network (Betw_road). Traditionally, having more subway stations, more convenient subway stations, higher road network density, and larger road network connectivity means having lower bus ridership. The intercity transport locational endowment is reflected by the distance to the airport (Dist_to_airport) and railway stations (Dist_to_rail station). Amongst, betweenness centrality measures the 
extent to which a particular node lies between other nodes in a bus network or road network, which reflects the inter-change role of the node (Jiao et al. 2017). The betweenness centrality of each station in the bus network and each road intersection in the road network are calculated according to the previous work by Wang et al. (2011), and then the betweenness centrality of each community in the bus and road network is calculated using IDW. The distance to bus stations, subway stations, airports, and rail stations is calculated using the software ArcGIS. The other data are mostly calculated according to the raw data sourced from a web mapping service application "Baidu Map".

The socio-economic attributes contain the Gross Domestic Product (GDP), population, employment, and average housing price in each community, which respectively measures the scale of GDP, population and employment divided by the areas of the community, and the average listing price of each residential quarter in each community. Considering that there is high collinearity between GDP and population-scale of communities, only the population scale, employment, and housing price are introduced in the models. The population and employment data are respectively sourced from Beijing population census data in 2010 and Beijing economic census data in 2014 (available at < http://gis.bjhgk.gov.cn/visual/ main/base.html?gallery $>$. accessed on 4 May 2016). The listing price of each residential quarter within the Six-Ring Road is collected from the website of Soufang (http://bj.fang. com/, accessed in December 2013), which is one of the famous real estate network media and information service enterprises.

The land use and built environment are evaluated using the density of education, catering, commercial facilities, financial spots, tourist spots, and healthcare, which are calculated using their number and the areas of the community where they are located in. Amongst, the number of these facilities is also sourced from "Baidu Map", while the area of each community is calculated using the software ArcGIS. Details about the dependent and independent variables are shown in Table 1.

\section{Methodology}

Spatial econometric models are widely used to capture spatial autocorrelation, which is referred to as the neighborhood effect or spatial autocorrelation (Jiao et al. 2020). Three widely used spatial econometric models, including the SEM, SLM, and SDM, are introduced. Specifically, the SDM accommodates the spatial interaction effect from the dependent variable and all explanatory variables, whereas the SLM and the SEM accommodate the spatial interaction effect only from the dependent and residual variables, respectively (Elhorst 2010). The formulas for the baseline, SDM, SEM, and SLM are as follows:

$$
\begin{gathered}
\text { SDM: } y=\rho W y+X \beta_{1}+W X \theta+\varepsilon \\
\text { SEM: } y=X \beta+\mu, \quad \mu=\lambda W \mu+\varepsilon \\
\text { SLM: } y=\rho W y+X \beta+\varepsilon
\end{gathered}
$$

where $y$ is the dependent variable, including the indicators reflecting the demand for bus ridership; X represents the constant and independent variables, including the external and internal factors influencing bus ridership; $\beta$ represents the corresponding parameters of each variable; and $\varepsilon$ is the residual of the model. W is the spatial weight matrix, which is 


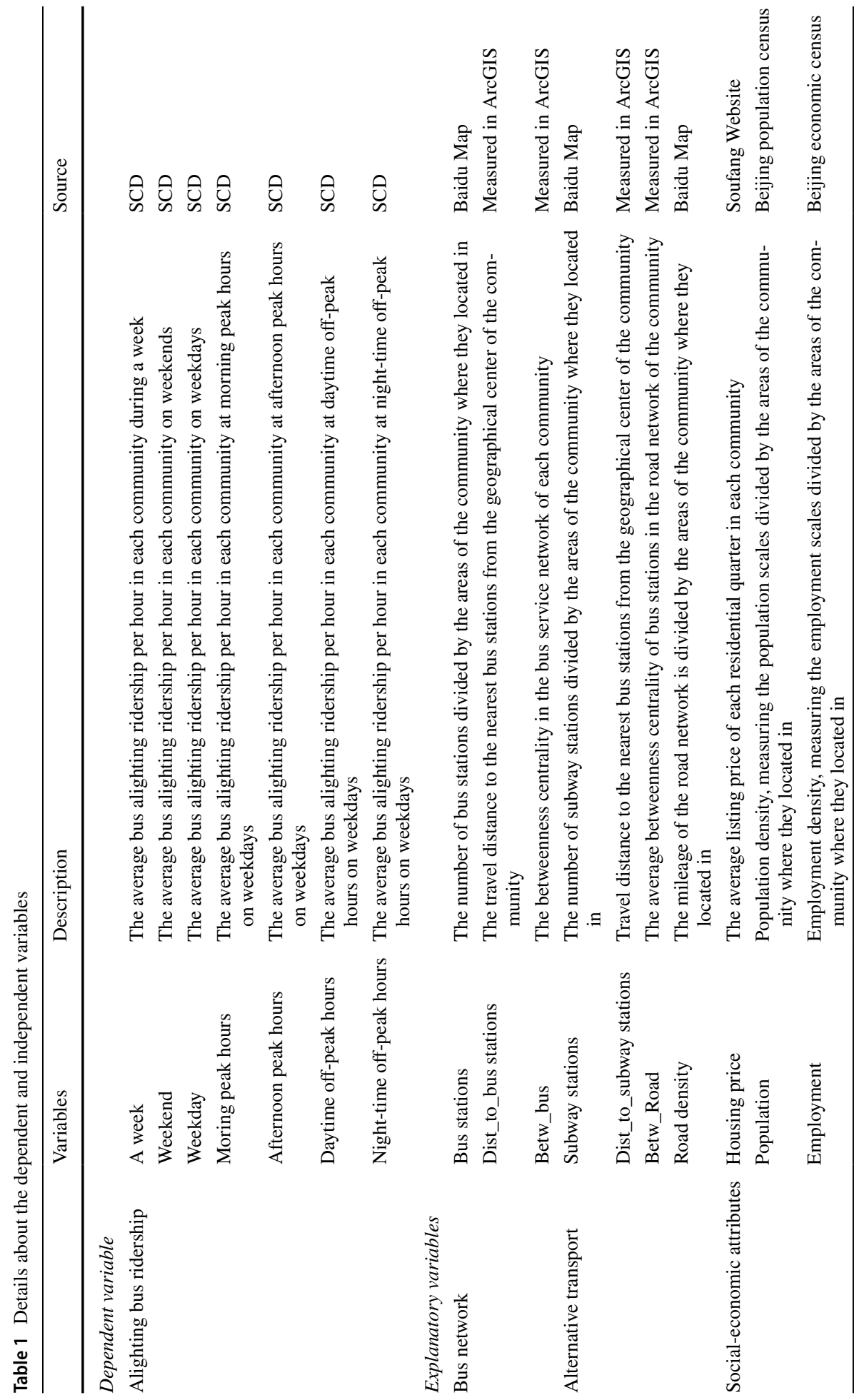




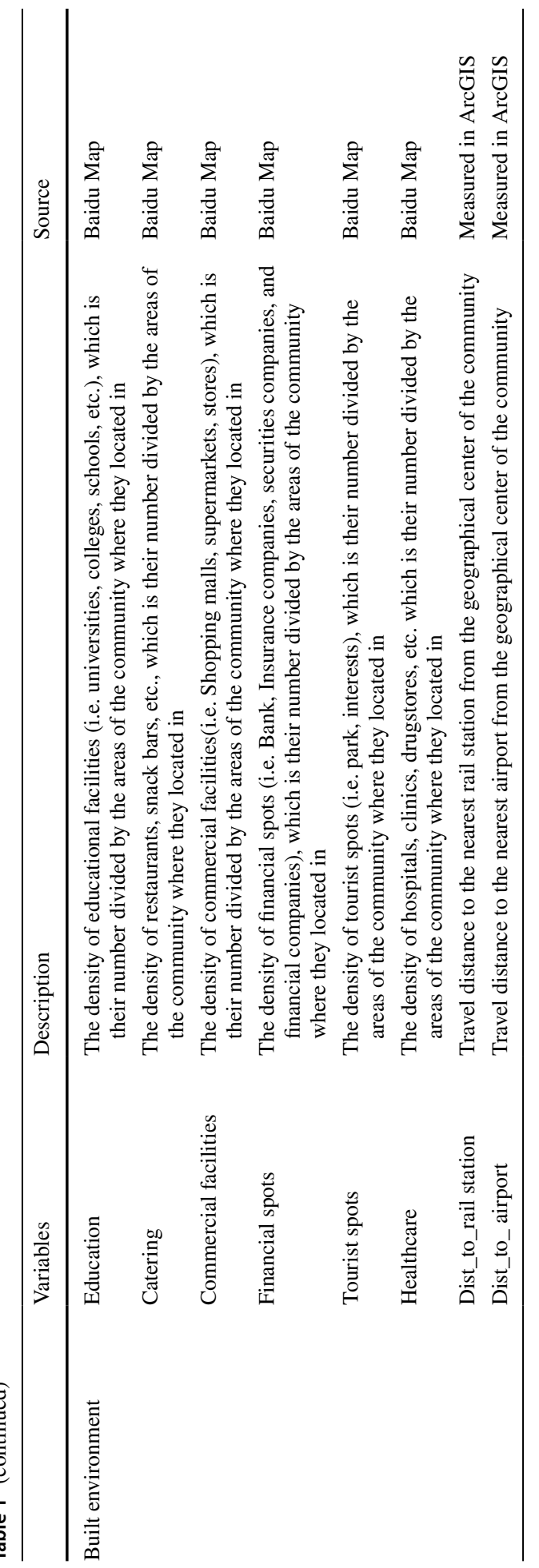


set as the inverse distance matrix, measuring the reciprocal of Euclidean distance between two communities. Wy represents the spatial lag in the dependent variable, indicating the spatially weighted average value of bus ridership from $i$ 's neighboring regions; WX is a spatial lag in the independent variables, which is the weighted average value of the independent from the neighbors. The coefficients $\rho$ and $\theta$ represent the effects of the dependent and independent variables for the neighboring regions, respectively, and $\lambda$ represents the spatial lag of the associated residual.

The selection of spatial econometric models is based on the following tests. First, the Lagrange multiplier (LM) diagnostics, including the Lagrange multiplier (LM) error test, LM-lag test, robust LM-error test, and robust LN-lag test, are used to judge whether spatial lag dependence or spatial error dependence exists in the model. Second, whether the SDM could be simplified, the SLM and SEM should be examined according to the values of $\rho$ and $\lambda$ (Elhorst, 2010; LeSage and Pace, 2009). When $\rho \neq 0$ and $\theta=\lambda=0$, SLM should be chosen; when $\rho=\theta=0$ and $\lambda \neq 0$, SEM should be chosen; when hypotheses of $\mathrm{H}_{0}: \theta=0$ and $\mathrm{H}_{1}: \theta+\rho \lambda=0$, tested using the Wald test, are rejected, the SDM is preferred over the spatial lag model (SLM) and the SEM.

\section{Spatiotemporal patterns of bus ridership}

\section{Temporal dynamics of bus ridership}

Figure 2 shows the aggregated hourly dynamics of bus usage concerning alighting ridership. The patterns are quite distinct on weekdays and weekends as well as at different time slots of the day. During weekdays, bus usage has shown stationarity patterns with two commuting peaks in the morning (6:30-10:00) and evening (16:30-20:00), indicating that most bus ridership occurs for commuters during the weekdays. Normally, bus ridership in the morning peak is higher than that in the evening peak. On weekends, both the morning and evening peaks still exist, but the total bus ridership during peak hours is much lower than that on weekdays, possibly because some commuters still work on weekends. The total bus ridership during off-peak hours on weekends is slightly higher than that on weekdays, indicating that more people choose to travel during off-peak hours on the weekends.

\section{Spatial dynamics of bus ridership}

Figure 3 shows the spatial patterns of average bus ridership per day during a week (Fig. 3a), weekday (Fig. 3b), and weekend (Fig. 3c) and the spatial disparity in bus ridership on weekdays and weekends (Fig. 3d), which is set as the difference between the average daily bus ridership on weekdays and that on weekends.

Bus ridership is mainly aggregated around transport hubs and residential areas (see Fig. 3). Specifically, the communities with high bus ridership align well with the intercity transport hubs (i.e., Beijing West station, Beijing South station, and Lianhuachi intercity bus station), the urban transport hubs (i.e., Dongzhimen station, Xizhimen station), and the central business district (CBD) and residential area (i.e., Huilongguan). This pattern is most explicit in Fig. 3a, which depicts bus usage on weekdays. This finding indicates that on weekdays, people are likely to commute by bus or travel to transport hubs by bus for transfer during a commuting journey. 
- - Monday $-O$ - Tuesday $-O-$ Wednesday $-O-$ Thursday $-O$ Friday $-O$ - Saturday $-O-$ Sunday

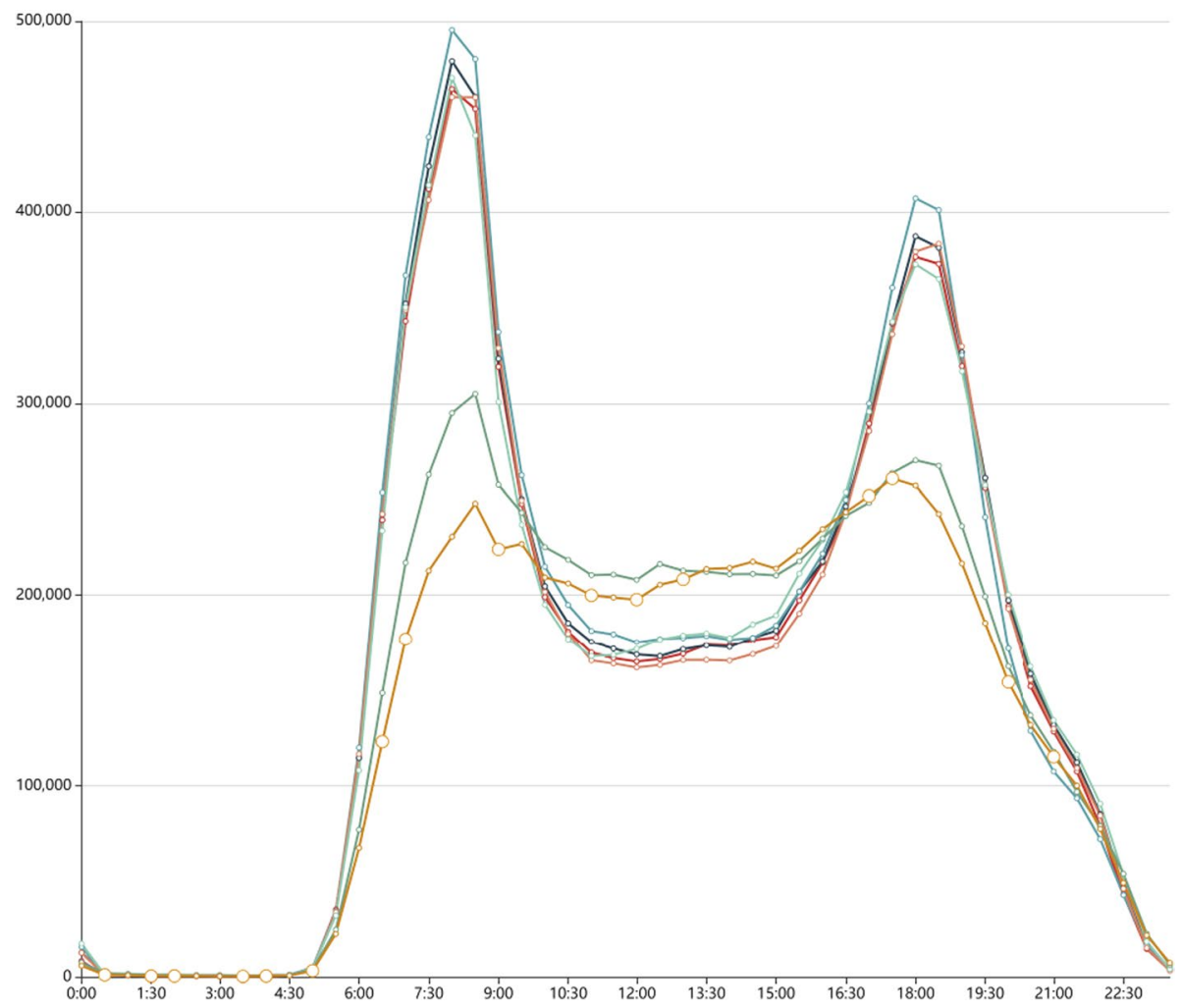

Fig. 2 Time-varying bus ridership during a week

To further investigate spatial disparity, the difference in average bus ridership between weekdays and weekends is explored (as shown in Fig. 3d). Of 3049 communities within the Six-Ring Road of Beijing, 2801 have more bus ridership on weekdays than weekends, which indicates that approximately $91.87 \%$ of communities have higher travel demand on weekdays than on weekends. These communities with large differences in average bus ridership between weekdays and weekends are mostly located near the CBD, transport hubs, and residential areas. The remaining $8.13 \%$ of communities have higher travel demand on weekends and are mainly located around tourist spots (i.e., South Luogu Lane, Tian'an Men, Happy Valley, Longtan Park) and some industrial parks.

We further explore the spatial dynamics of bus ridership at peak and off-peak hours on weekdays. Figure 4 illustrates the spatial dynamics of average bus ridership hourly during morning peak hours (Fig. 4a), evening peak hours (Fig. 4b), daytime off-peak hours (Fig. 4c), and night-time off-peak hours (Fig. 4d) on weekdays.

The bus ridership during morning and afternoon peak hours share large similarities with the total on weekdays, and communities located around transport hubs or with large residential populations have larger volumes of bus ridership than other places. According to the difference between the hourly bus ridership during morning and afternoon peak hours, we find that most communities have larger bus ridership during morning peak hours than 

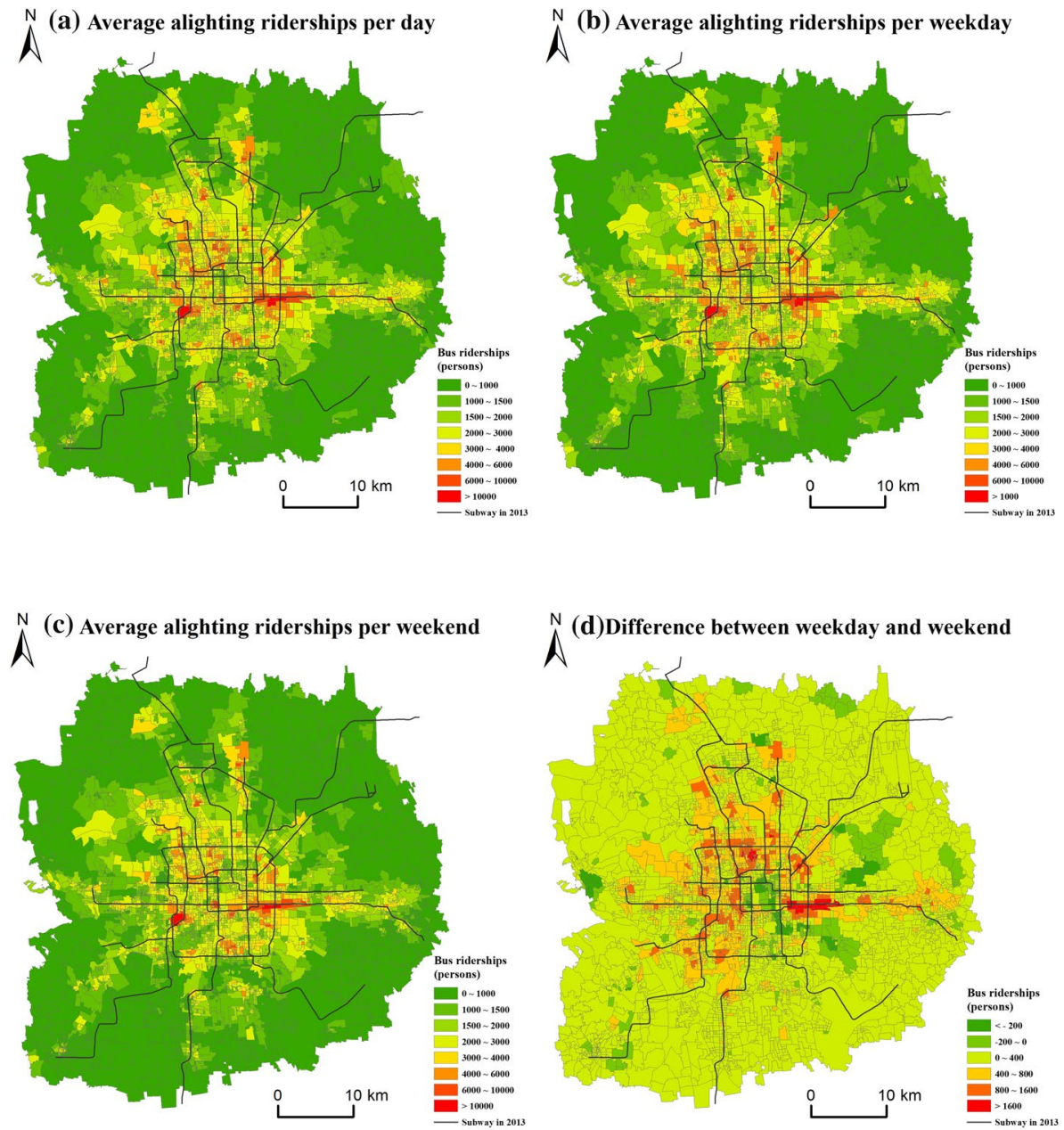

Fig. 3 Spatial patterns of average ridership per day on weekdays and weekends

during afternoon peak hours, indicating that residents are apt to use bus services for commuting in the morning. Possible reasons are that in Beijing, most people go to work at the similar times, but they finish work at different times in the afternoon since some of them work overtime. Moreover, elderly people in Beijing, who are free to take the bus, are more likely to go shopping or go to the park in the early morning, which might also increase bus ridership during morning peak hours. The alighting ridership during morning peak hours is mainly concentrated at the transport hubs and job centers of Beijing (Zhongguancun, Guomao, etc.), while that in residential communities are concentrated during afternoon peak hours. 


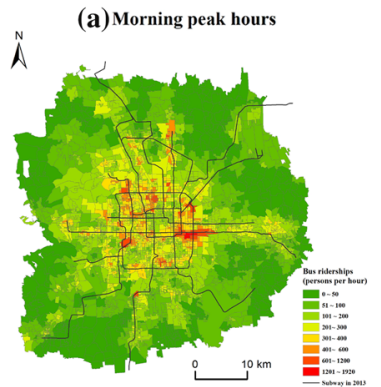

(b) Afternoon peak hours

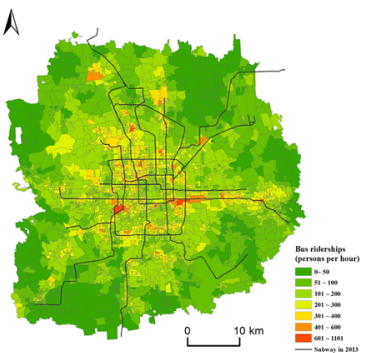

N (d) Daytime off-peak hours

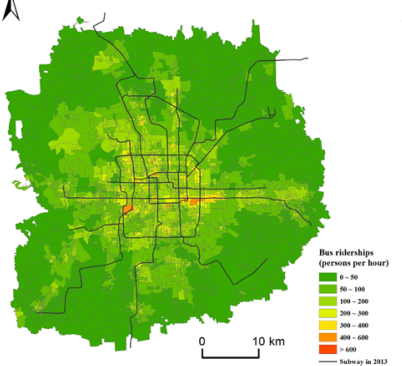

$\bigwedge^{N} \quad$ (e) Night-time off-peak hours

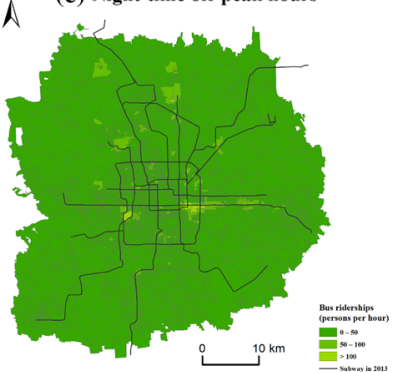

$\bigwedge^{N}$

(c) Difference between morning

A and afternoon peak hours

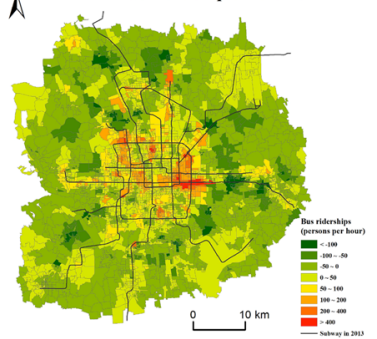

Fig. 4 Spatial patterns of bus ridership at different time slots during weekdays

\section{Regression estimate results}

In this section, the determinants of bus ridership are investigated from the perspective of different time slots, including weekdays and weekends, morning and afternoon peak hours, and daytime and night-time off-peak hours among weekdays. According to the results of a heteroscedasticity test, feasible generalized least squares (FGLS) are introduced to estimate the spatial econometric models. According to the results of the LM, LR, and Wald tests, the SDM is preferred over the SLM and the SEM. The estimated results are shown in Figs. 5, 6, 7 .

\section{Impacts of transport endowment}

Figure 5 shows the coefficients of the transport endowment and their spatial lag, which respectively reflect how the transport endowment of a community and its neighbors impact its bus ridership; thus, a positive coefficient for the density of bus stations and subway stations, betweenness centrality in road and bus network, and road density, and a negative coefficient for distance to bus stations, subway stations, rail stations, and airports, meaning that the transport endowment in a community and its neighbors have a negative influence on its bus ridership.

The betweenness centrality in the bus network and road network and the distance to subway stations and rail stations had a significant influence on bus ridership at all the selected time slots (Fig. 5). The elasticities of these indicators were higher than the other significant indicators at all the selected time slots. That is, there might be more bus ridership in the 

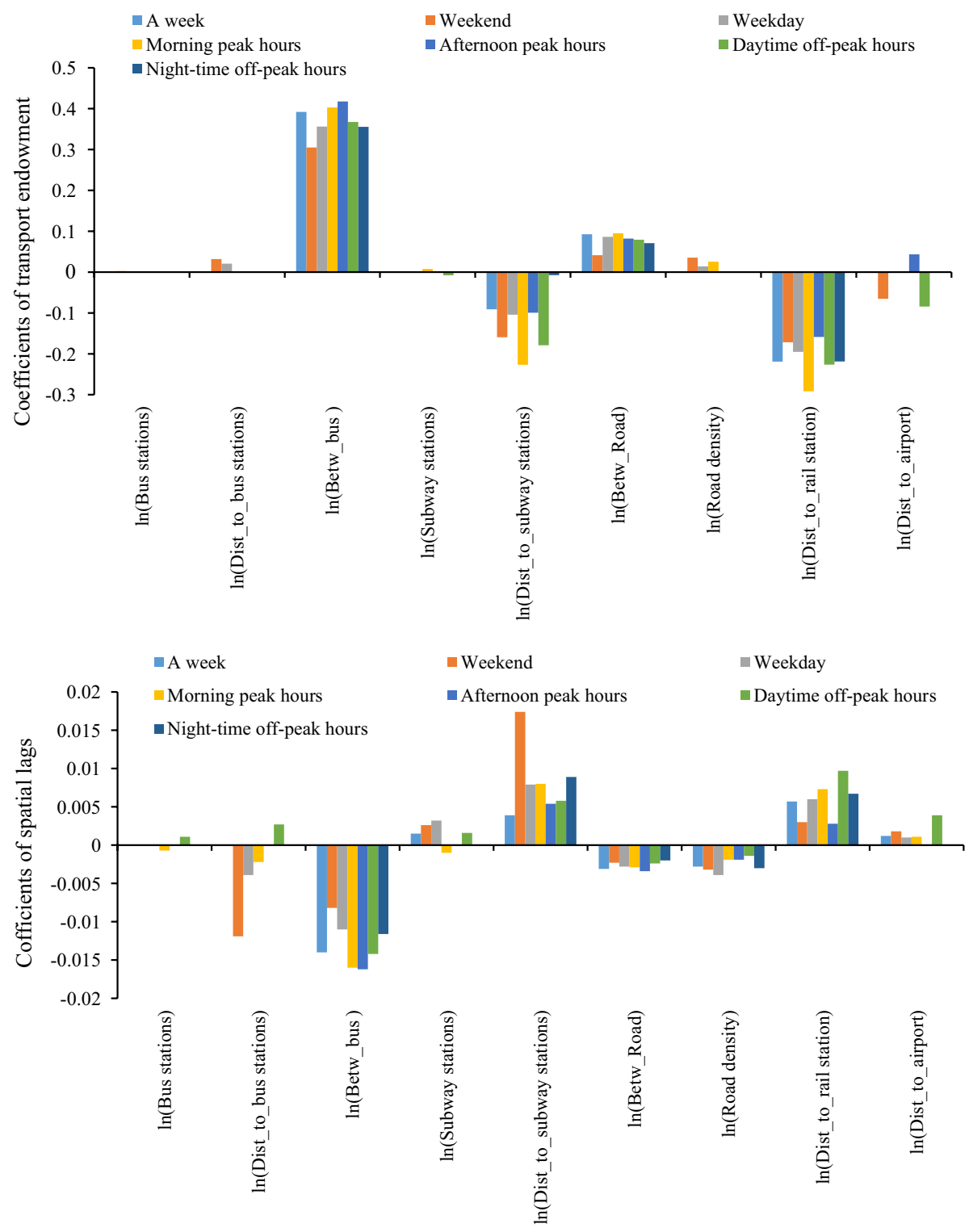

Fig. 5 Elasticity of transport variables on bus alighting ridership

communities with higher betweenness centrality, and lower distance to the subway station, which respectively reflected the transferring role in bus and road network, and the accessibility to subway stations. The positive influence of betweenness centrality in bus and road network and negative influence of the distance to subway stations and rail station indicated that persons are more likely to transfer from one bus to another bus, or even to subway or railway. Except for the distance to subway stations, the impact magnitude of the other three indicators on weekdays was higher than that on weekends. On both weekdays and 

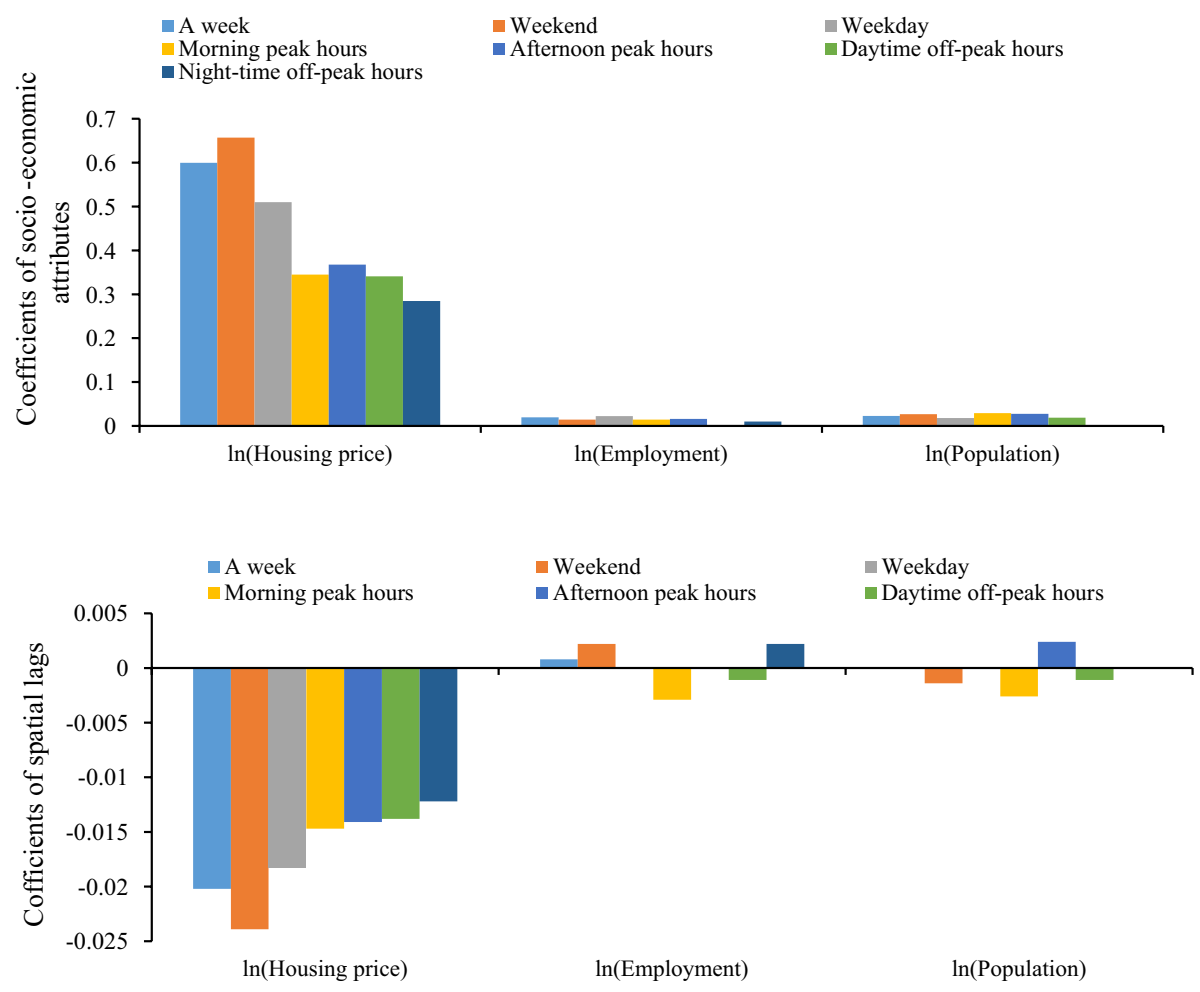

Fig. 6 Elasticity of social-economic attributes on bus alighting ridership

weekends, bus ridership was also influenced by the distance to bus stations and road density, and the magnitude of the impact of these two indicators on weekdays was lower than that on weekends. That's to say, the transport connectivity, reflected by the betweenness centrality, had generated a larger influence on the bus ridership on weekdays, while the density and accessibility respectively donated by the road density and distance to bus stations had generated a larger affect on the bus ridership on weekends.

Concerning the four-time slots on weekdays, the betweenness centrality in the road network, the distance to subway stations and rail station generated the largest influence on bus ridership during morning peak hours but the smallest influence at night-time off-peak hours or afternoon peak hours; the betweenness centrality in the bus network generated the largest influence on bus ridership during afternoon peak hours but the smallest influence at night-time off-peak hours. Additionally, the density of subway stations and road density had a significantly positive influence on bus ridership during morning peak hours, but the density of subway stations had a negative influence during daytime off-peak hours. Overall, the bus ridership during morning peak hours were more impacted by the betweenness centrality in the road network, the distance to subway stations and rail station, and subway density than the other time slots, while that during afternoon peak hours were more likely to be influenced by the betweenness centrality in the bus network.

The spatial lag of the betweenness centrality in the bus network and road network and road density generated a significantly negative influence on bus ridership at all the selected 


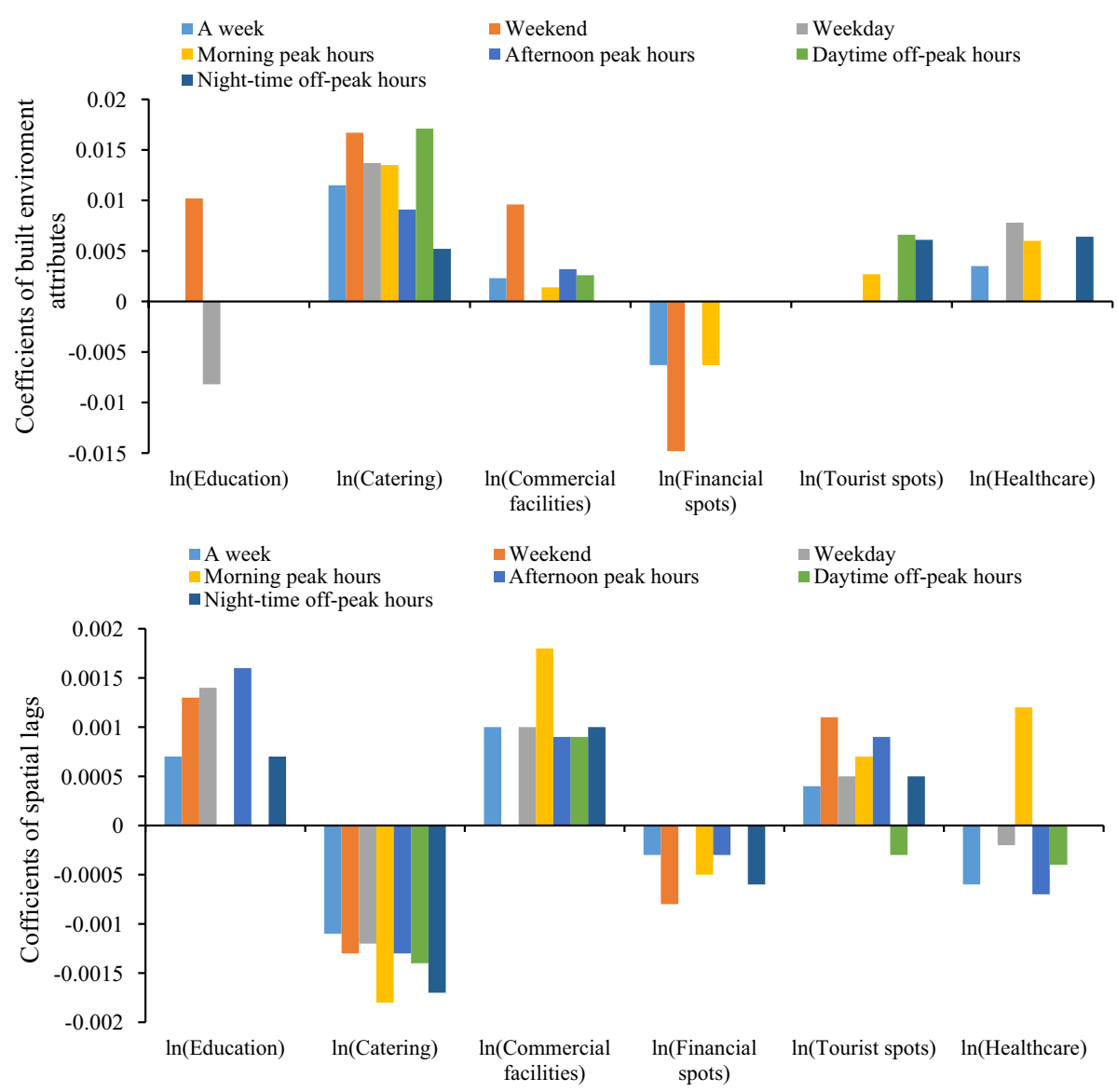

Fig. 7 Elasticity of built environment indicators on bus alighting ridership

time slots, indicating that an increase in these indicators of a community's neighbors had a negative influence on its bus ridership (Fig. 5). The spatial lag of the distance to subway stations, airport, and rail stations had a significant positive influence on bus ridership at all the selected time slots, indicating that an increase in the distance to subway stations, airport and rail station of a community's neighbors might have an overall positive influence on bus ridership. Bus ridership on weekdays was more sensitive to a decrease in betweenness centrality in the bus network and road network, a decrease in road density, and an increase in the distance to the airport than on weekends. Bus ridership was more sensitive to an increase in the density of subway stations and a decrease in the distance to bus stations and rail stations on weekends than on weekdays. Concerning the four-time slots on weekdays, bus ridership during afternoon peak hours was most sensitive to the increased betweenness centrality in the bus network and road network and the road density of its neighbors than the other three time slots. Bus ridership at daytime off-peak hours was most sensitive to the increased distance to subway stations and airports. Bus ridership at all the time slots was more influenced by the betweenness centrality in the bus network of its neighbors than by the other indicators. 


\section{Impacts of socioeconomic attributes}

Figure 6 shows the coefficients of the social-economic attributes (including housing price, employment, and population) and their spatial lag, which respectively represent the impacts of social-economic attributes of a community and its neighbors on its bus ridership; thus, a positive coefficient means that the housing price, employment, and population of a community and its neighbors have a positive influence on its bus ridership.

Housing price, employment, and population all had positive impacts on bus ridership on weekends and weekdays. The impact magnitude of housing price and the population was greater on weekends than on weekdays, but the impact magnitude of employment was greater on weekdays than on weekends. Specifically, the elasticities of housing price and population were respectively 0.5097 and 0.0180 on weekdays, which were lower than those on weekends (0.6569 and 0.0267), indicating that housing prices and the population had generated a larger influence on the bus ridership on weekends than that on weekdays. The elasticity of employment was 0.0225 on weekdays, 0.0195 in a week, and 0.0145 on weekends. The impact magnitude on weekdays was higher than that on weekends, indicating that employment had generated a larger influence on the bus ridership on weekdays than that on weekends.

Concerning the time slots on weekdays, both housing price and employment generated the largest influence on bus ridership during afternoon peak hours but the smallest influence at night-time off-peak hours; population generated the largest influence on bus ridership during morning peak hours but the smallest influence at daytime off-peak hours. Specifically, the elasticities of housing price and employment during afternoon peak hours (0.3676 and 0.0159$)$ were slightly higher than those during morning peak hours $(0.3450$ and 0.0143$)$, daytime off-peak hours (0.3410 and not significant), and much higher than those during night-time off-peak hours (0.2845 and 0.0099), indicating that housing prices and employment had a larger influence on bus ridership during afternoon peak hours than during the other time slots. The elasticity of the population during morning peak hours (0.0290) was higher than that during afternoon peak hours (0.0277) and at daytime offpeak hours (0.0189), indicating that the population had a larger influence on the bus ridership during morning peak hours than during the other time slots.

Concerning the spatial neighbouring effects, the housing price in a community's neighbors generated a negative influence on bus ridership in a week, weekdays, weekends, and all four-time slots. The population in a community's neighbors had a negative influence on bus ridership on weekends, during morning peak hours, and daytime off-peak hours on weekdays, but a positive effect on bus ridership during afternoon peak hours. The employment in a community's neighbors had a positive influence on bus ridership on weekends and during night-time off-peak hours, but a negative influence on bus ridership during morning peak hours and daytime off-peak hours.

\section{Impacts of built environment attributes}

Figure 7 shows the coefficient related to the built environment attributes and their spatial lag, which respectively represent the impacts of density indicators in a community and of its neighbors on its bus ridership; thus, a positive coefficient means that the density indicators in a community and its neighbors have a positive influence on its bus ridership.

Education and catering had a significant influence on bus ridership on both weekends and weekdays, but the impact magnitude on bus ridership on weekends was higher than 
that on weekdays. Specifically, the elasticities of education and catering on weekends were respectively 0.0102 and 0.0167 , which were higher than the values of -0.0082 and 0.0137 on weekdays. Possible reasons might be that during the weekends, people have more spare time to visit catering and that university students are more likely to go off campus for shopping and entertainment. Healthcare had a positive influence on bus ridership on weekdays but no significant influence on weekends. That is, healthcare was one of the key determinants of bus ridership on weekdays instead of weekends, possibly because most hospital departments are closed on weekends. Commercial facilities and financial spots had a significantly positive influence on bus ridership on weekends but no significant influence on bus ridership on weekdays. Specifically, the elasticities of commercial facilities and financial spots were respectively 0.0096 and -0.0148 on weekends, which indicated that the higher the commercial facilities and the lower the financial spots, the higher the bus ridership of a community on weekends. The density of tourism spots had no significant influence on bus ridership on either weekdays or weekends.

Concerning the time slots on weekdays, bus ridership at daytime off-peak hours was more sensitive to catering and tourist spots than the other time slots, while the bus ridership during morning peak hours and afternoon peak hours were more sensitive to the healthcare and commercial facilities, respectively. Specifically, the elasticities of catering and tourist spots during daytime off-peak hours (0.0171 and 0.0066) were higher than those during morning peak hours $(0.0135$ and 0.0027$)$, afternoon peak hours $(0.0091$ and not significant), and night-time off-peak hours (0.0052 and 0.0061), indicating that having higher catering and tourist spots of a community had the largest influence on bus ridership during daytime off-peak hours. Healthcare had a significantly positive influence on bus ridership during the morning peak hours but was not significant during the other time slots. The elasticity of commercial facilities during afternoon peak hours was 0.0032 , which was higher than that during daytime off-peak hours (0.0026).

The spatial lag of the built environment indicators all had a significant influence on bus ridership in a week, but the impact varied across different time slots. Specifically, the average bus ridership in a community was positively impacted by the education, commercial facilities, and tourist spots of its neighbors but negatively influenced by the catering, financial spots, and healthcare. Thus, the increased education, commercial facilities, and tourist spots of neighbors generated a positive influence on bus ridership, but the large catering, financial spots, and healthcare of neighbors generated a negative influence. Similar results could be found for the selected time slots, except that there was no significant influence of education during morning peak hours and daytime off-peak hours, of commercial facilities on weekends, or financial spots on weekday and daytime off-peak hours; there was a negative influence of tourist spots during daytime off-peak hours and a positive influence of healthcare during morning peak hours. The magnitude of the impact of the catering, financial spots, and tourist spots of neighbors was higher on weekends than on weekdays, while that of the education, commercial facilities, and healthcare of neighbors was higher on weekdays than on weekends. Bus ridership during morning peak hours was more sensitive to the catering, commercial facilities, and healthcare of neighbors than bus ridership in the other three-time slots on weekdays, while that during afternoon peak hours was most sensitive to the education and tourist spots of neighbors. 


\section{Robustness and endogeneity test}

The estimation of spatial econometric models might be influenced by the setting of the weight matrix. Commonly, the weight matrix can be built based on the adjacency matrix, the inverse distance, the transport distance, or the travel time (e.g., Bottasso et al. 2014; Feng et al. 2019). Since the transport distance and the travel time could be reflected by the transport indicators in our model, this study adopts the adjacency matrix as a substitution for inverse distance. Thus, the robustness test is implemented by replacing the inverse distance matrix with the adjacent matrix.

After replacing the inverse distance square matrix with the adjacent matrix in the SDM, the results showed that the betweenness centrality in the bus network, distance to subway stations, betweenness centrality in the road network, road density, housing price, employment, education, commercial facilities, tourist spots and healthcare all had similar influences on bus ridership (see Table 2). That is, the influence of these indicators on bus ridership was not influenced by the matrix setting. There were also some indicators with different influences on bus ridership after replacing the inverse distance square matrix with the adjacent matrix in the SDM. In the model with an adjacent matrix, the bus stations had a positive influence on the bus ridership on weekends and a negative influence on that in a week; the distance to bus stations has a negative influence on bus ridership in a week and daytime off-peak hours; the distance to the airport has a positive influence on bus ridership in a week, on weekends and weekdays, and during three-time slots; the distance to rail station had a positive influence on bus ridership on weekends, while financial spots had a positive influence on bus ridership on weekends; population and catering had a negative influence on bus ridership in a week, and financial spots had a positive influence on bus ridership on weekends. All these indicators showed different influences on bus ridership compared with the baseline model.

To test for potential endogeneity problems, the Hausman specification test and overidentification are introduced. First, the Hausman specification test is employed to detect whether endogeneity has a significant impact on the results by comparing the estimation results with and without instrumental variables (IVs). If the estimations are not significantly different, this reveals significant endogeneity that affects the robustness of the estimation results. According to the data availability and indicator characteristics, the revenue income of each community is chosen as the IV for the population. The results of the Hausman test show that all the variables in our models are exogenous. Second, the over-identification test is employed to detect whether the IVs and the corresponding variables are strictly exogenous, and the results show that the revenue income is strictly exogenous and could thus be chosen as the IV for the population (Table 3). Overall, there are no endogeneity problems in the model.

\section{Conclusions and discussions}

This study attempted to explore the temporal and spatial dynamics and determinants of public transport ridership at the community level, considering the spatial autocorrelation and neighboring effects. The major findings of this studies can be summarized as follows:

1. The temporal dynamics were quite distinct on weekdays and weekends as well as at different time slots per day. Bus usage on both weekdays and weekends showed sta- 


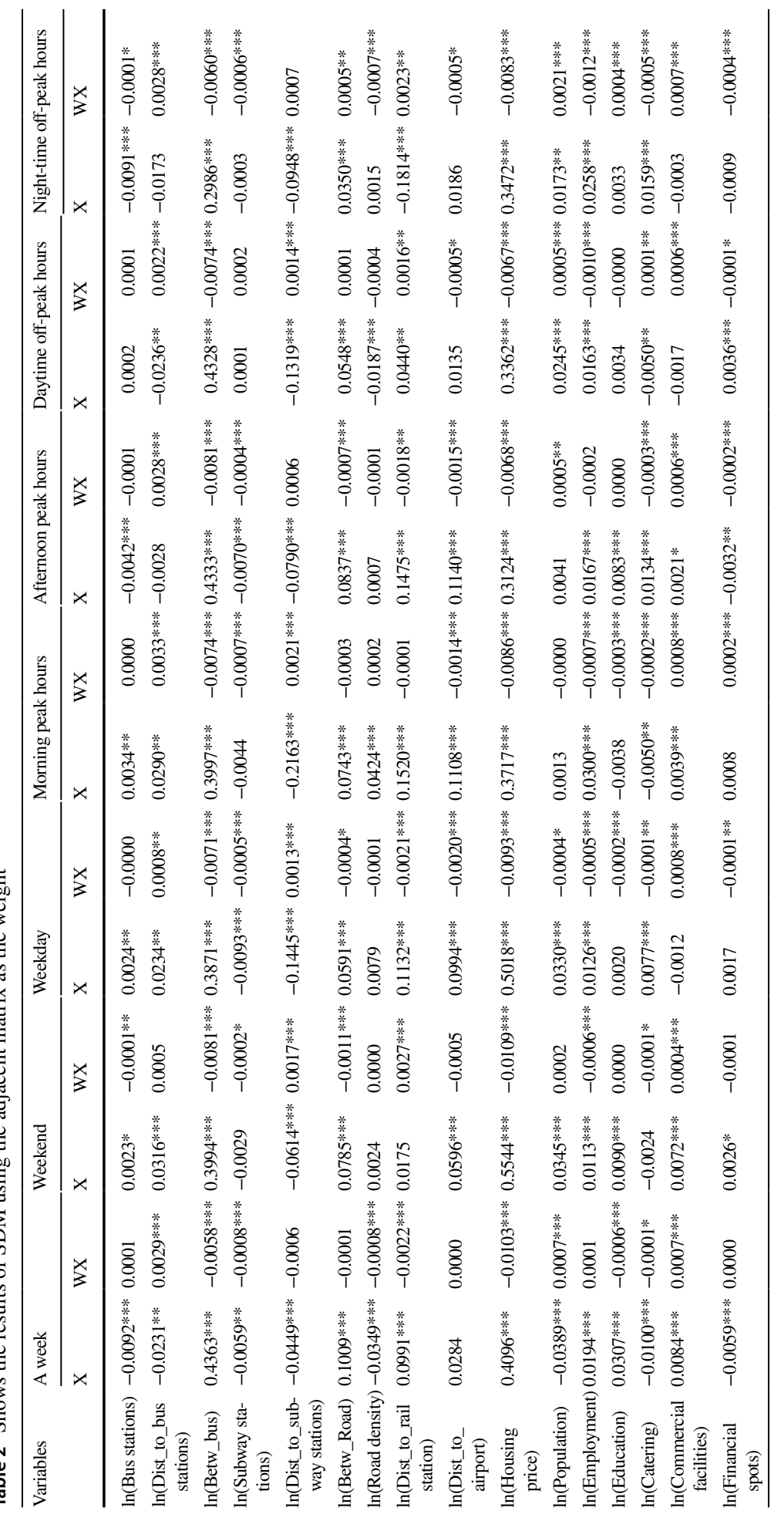




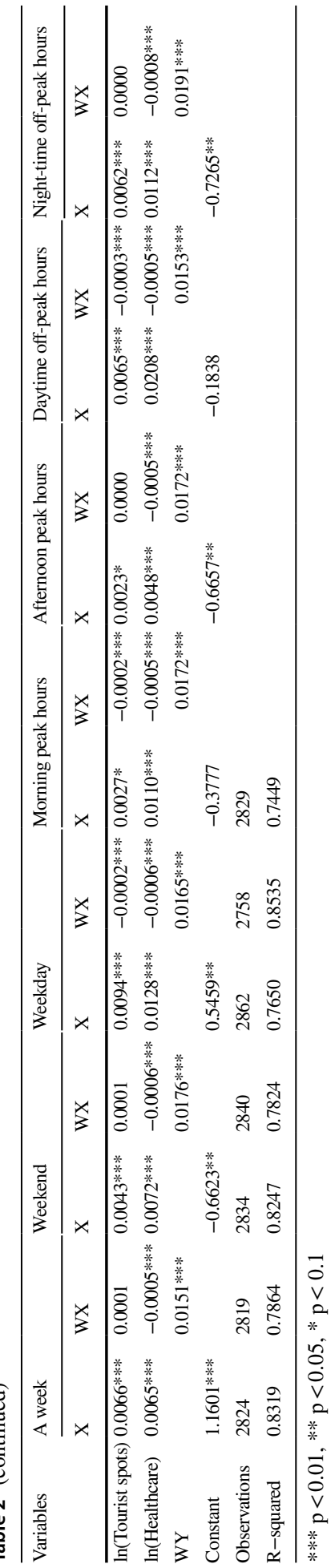


Table 3 Results of over-identification test

\begin{tabular}{llllllll}
\hline & A week & Weekend & Weekday & $\begin{array}{l}\text { Morn- } \\
\text { ing peak } \\
\text { hours }\end{array}$ & $\begin{array}{l}\text { Afternoon } \\
\text { peak hours }\end{array}$ & $\begin{array}{l}\text { Daytime } \\
\text { off-peak } \\
\text { hours }\end{array}$ & $\begin{array}{l}\text { Night-time } \\
\text { off-peak } \\
\text { hours }\end{array}$ \\
\hline chi $^{2}(35)$ & 1.36 & 0.76 & 1.36 & 2.38 & 1.40 & 0.35 & 0.09 \\
Prob & 1.0000 & 1.0000 & 1.0000 & 1.0000 & 1.0000 & 1.0000 & 1.0000 \\
Sargan N*R-sq test & 0.754 & 0.615 & 1.218 & 5.905 & 0.189 & 1.863 & 0.538 \\
Chi-sq(1) P-value & 0.3852 & 0.4330 & 0.2697 & 0.0152 & 0.6634 & 0.1723 & 0.4631 \\
Basmann test & 0.745 & 0.607 & 1.204 & 5.843 & 0.187 & 1.841 & 0.532 \\
Chi-sq(1) P-value & 0.3881 & 0.4359 & 0.2726 & 0.0156 & 0.6653 & 0.1749 & 0.4659 \\
\hline
\end{tabular}

tionarity patterns with two commuting peaks in the morning (6:30-10:00) and evening (16:30-20:00). The total bus ridership during peak hours on weekends was much lower than that on weekdays. The total bus ridership during off-peak hours on weekends was slightly higher than that on weekdays.

2. The communities with high bus ridership were mostly located near the CBD, transport hubs, and residential areas on both weekends and weekdays and across different time slots during weekdays. Moreover, $91.87 \%$ of communities had higher travel demand on weekdays than on weekends, and most of the communities had higher bus ridership during morning peak hours than during afternoon peak hours on weekdays. The communities with higher travel demand on weekends were mostly located in tourist spots (i.e., South Luogu Lane, Tian'an Men, Happy Valley, Longtan Park) and some industrial parks.

3. The impacts of each determinant varied across weekends, weekdays, and the different time slots on weekdays. The betweenness centrality in both the bus network and road network, distance to the rail stations, employment, and healthcare generated a larger influence on bus ridership on weekdays than on weekends, while the distance to subway stations, road density, housing price, population, education, catering, and commercial facilities generated a larger influence on weekends than on weekdays. The subway station density, distance to subway stations, betweenness centrality in the road network, road density, distance to the airports, population, catering, financial spots, and healthcare generated a larger influence on bus ridership at morning peak hours than at the other time slots. The betweenness centrality in the bus network and employment generated a larger influence on bus ridership during afternoon peak hours than during the other time slots.

4. The bus ridership of a community was impacted by factors of its neighbors, as reflected in the highly significant spatial autocorrelation effect. For example, the density and distance to subway stations, to the airport, and rail stations of the community's neighbors had a positive influence on bus ridership on both weekdays and weekends. Hence, the farther a community's neighbors were located from subway stations, airports, and rail stations, the higher the bus ridership of a community. The housing price and betweenness centrality in both the bus network and road network of the communities' neighbors generated a negative influence on bus ridership.

This study can be fruitfully extended along several avenues. First, this paper explores the temporal and spatial dynamics of bus ridership using the aggregate data of each 
community in Beijing, instead of using the origin to destination linked transit trips between the boarding and alighting stations, which could reflect the flow characteristics between stations. Future studies are expected to investigate the temporal and spatial dynamics of the origin to destination linked transit trips. This is particularly relevant in the context of bus schedule arrangement and public transport planning. Second, while this paper explored the temporal and spatial dynamics of bus ridership and its determinants at different time slots using a global model, the local effects of the determinants using the geographicallyweighted regression (GWR) on bus ridership are not considered. This topic deserves a profound study in the future. Third, this paper only considers the available indicators at the community level, resulting in that some of the unavailable data of the key determinants of bus ridership might not be considered. Empirical evidence (e.g., Kuai and Wang, 2020) suggested that the indicators at a larger spatial scale than the community level (e.g. study area) could be used as the alternative indicators of the unavailable data, and the semi-parametric geographically-weighted regression (SGWR) could reveal the effects of both the global and local factors on the public transit ridership. It is of our interest to examine the influence of the unavailable key determinants on bus ridership.

\section{Policy implications}

Several important policy implications for increasing bus ridership and transport planning in Beijing. The first implication is generated from the temporal and spatial dynamics of bus ridership. In this study, the hot areas and peak hours of bus ridership were detected. Specifically, the bus ridership was mainly concentrated during the morning and afternoon peak hours on the weekday and is located near the $\mathrm{CBD}$, transport hubs, and residential areas. It might be necessary to dynamically adjust the bus schedule by increasing the number of bus services during peak hours and at the hot areas for increasing bus usage.

Secondly, it might be significant to improve the transferring efficiency of the transport network and to increase the transport supply at the communities with high social-economic and built environment attributes for increasing bus ridership. The betweenness centrality in both road and bus networks, which reflects the inter-change role or the transferring efficiency of a community in the transport network, had generated a positive influence on bus ridership at all the selected time slots. This implies that improving the inter-change role of a community in the transport network, especially in road networks might increase bus usage. The positive influence of housing price, employment, and population on bus ridership means that the increase in these social-economic indicators might induce more demand for bus services, and then more supply for bus services. The induced demand for bus services in the communities with high housing prices, employment, and population should be considered in comprehensive transport system planning, especially public transport planning.

The third implication could be derived from the significant influence of spatial lag on bus ridership. The negative influence of the attributes of its neighbors on a community's bus ridership revealed that the improvement in the transport endowment of a community's neighbors might largely reduce its transport demand. This implies that improving the transport endowment of a community's neighbors might be an effective role to reduce its bus crowing and induce more travel demand for bus services. 
Acknowledgements The authors would like to acknowledge the research support received from the National Natural Science Foundation of China (Grant No. 41701126, 42071147), and the Social Science Foundation of Beijing (Grant No. 21JJB009).

Open Access This article is licensed under a Creative Commons Attribution 4.0 International License, which permits use, sharing, adaptation, distribution and reproduction in any medium or format, as long as you give appropriate credit to the original author(s) and the source, provide a link to the Creative Commons licence, and indicate if changes were made. The images or other third party material in this article are included in the article's Creative Commons licence, unless indicated otherwise in a credit line to the material. If material is not included in the article's Creative Commons licence and your intended use is not permitted by statutory regulation or exceeds the permitted use, you will need to obtain permission directly from the copyright holder. To view a copy of this licence, visit http://creativecommons.org/licenses/by/4.0/.

\section{References}

An, D., Tong, X., Liu, K., Chan, E.H.W.: Understanding the impact of built environment on metro ridership using open source in Shanghai. Cities 93, 177-187 (2019). https://doi.org/10.1016/j.cities.2019.05.013

Boame, A.K.: The technical efficiency of Canadian urban transit systems. Transp. Res. E Log. Transp. Rev. 40(5), 401-416 (2004). https://doi.org/10.1016/j.tre.2003.09.002

Bottasso, A., Conti, M., Ferrari, C., Tei, A.: Ports and regional development: a spatial analysis on a panel of European regions. Transp. Res. A Policy Pract. 65, 44-55 (2014). https://doi.org/10.1016/j.tra.2014. 04.006

Buehler, R.: Determinants of transport mode choice: a comparison of Germany and the USA. J. Trans. Geograp. 19(4), 644-657 (2011). https://doi.org/10.1016/j.jtrangeo.2010.07.005

Cervero, R., Kockelman, K.: Travel demand and the 3Ds: density, diversity, and design. Transp. Res. D Trans. Environ. 2(3), 199-219 (1997). https://doi.org/10.1016/S1361-9209(97)00009-6

Chakour, V., Eluru, N.: Examining the influence of stop level infrastructure and built environment on bus ridership in Montreal. JTRG 51, 205-217 (2016)

Chen, E., Ye, Z., Wang, C., Zhang, W.: Discovering the spatio-temporal impacts of built environment on metro ridership using smart card data. Cities 95, 1-14 (2019). https://doi.org/10.1016/j.cities.2019. 05.028

Chiou, Y., Jou, R., Yang, C.: Factors affecting public transportation usage rate : geographically weighted regression. Transp. Res. A Policy Pract. 78, 161-177 (2015). https://doi.org/10.1016/j.tra.2015.05. 016

Chow, L.F., Zhao, F., Liu, X., Li, M.T., Ubaka, I.: Transit ridership model based on geographically weighted regression. Transp. Res. Rec. 1972(1), 105-114 (2006)

Chu, X.: Ridership models at the stop level. In: National Center for Transit Research, University of South Florida (2004).

Currie, G., Delbosc, A.: Understanding bus rapid transit route ridership drivers: an empirical study of Australian BRT systems. Transp. Policy 18(5), 755-764 (2011). https://doi.org/10.1016/j.tranpol. 2011.03.003

Du, F., Mao, L., Wang, J., Jin, H.: Inferring transit-based health seeking patterns from smart card data: a case study in Beijing, China. Health Place (2020). https://doi.org/10.1016/j.healthplace.2020.102405

Elhorst, J.P.: Matlab Software for Spatial Panels. Presented at the IVth World Conference of the Spatial Econometrics Association (SEA), Chicago, June 9-12 (2010). http://www.regroningen.nl/elhorst/ doc/Matlab-paper.pdf

Feng, Y., Wang, X., Du, W., Wu, H., Wang, J.: Effects of environmental regulation and FDI on urban innovation in China: a spatial Durbin econometric analysis. J. Clean. Prod. 235, 210-224 (2019). https://doi.org/10.1016/j.jclepro.2019.06.184

Gruyter, C.D., Truong, L.T., Taylor, E.J.: Can high quality public transport support reduced car parking requirements for new residential apartments? J. Transp. Geograp. 82, 102627 (2020). https://doi. org/10.1016/j.jtrangeo.2019.102627

Gutiérrez, J., Cardozo, O.D., García-Palomares, J.C.: Transit ridership forecasting at station level: an approach based on distance-decay weighted regression. J. Transp. Geograp. 19(6), 1081-1092 (2011). https://doi.org/10.1016/j.jtrangeo.2011.05.004

He, Y., Zhao, Y., Tsui, K.L.: Exploring influencing factors on transit ridership from a local perspective. Smart Resil. Transp. 1, 2-16 (2019) 
Huang, J., Levinson, D., Wang, J., Jin, H.: Job-worker spatial dynamics in Beijing: insights from smart card data. Cities 86, 83-93 (2019). https://doi.org/10.1016/j.cities.2018.11.021

Ingvardson, J.B., Nielsen, O.A.: How urban density, network topology and socio-economy influence public transport ridership: empirical evidence from 48 European metropolitan areas. J. Transp. Geograp. 72, 50-63 (2018). https://doi.org/10.1016/j.jtrangeo.2018.07.002

Jiao, J., Wang, J., Jin, F.: Impacts of high-speed rail lines on the city network in China. J. Transp. Geograp. 60, 257-266 (2017). https://doi.org/10.1016/j.jtrangeo.2017.03.010

Jiao, J., Wang, J., Zhang, F., Jin, F., Liu, W.: Roles of accessibility, connectivity and spatial interdependence in realizing the economic impact of high-speed rail: Evidence from China. Transp. Policy 91, 1-15 (2020). https://doi.org/10.1016/j.tranpol.2020.03.001

Jun, M.J., Choi, K., Jeong, J.E., Kwon, K.H., Kim, H.J.: Land use characteristics of subway catchment areas and their influence on subway ridership in Seoul. J. Transp. Geograp. 48, 30-40 (2015). https://doi.org/10.1016/j.jtrangeo.2015.08.002

Kuai, X., Wang, F.: Global and localized neighborhood effects on public transit ridership in Baton Rouge, Louisiana. Appl. Geograp. 124, 102338 (2020). https://doi.org/10.1016/j.apgeog.2020.102338

Kuby, M., Barranda, A., Upchurch, C.: Factors influencing light-rail station boardings in the United States. Transp. Res. A Policy Pract. 38(3), 247 (2004). https://doi.org/10.1016/j.tra.2003.10.006

LeSage, J.P., Pace, R.K.: Introduction to Spatial Econometrics. CRC Press, Taylor \& Francis Group, Boca Raton (2009)

Li., X., Liu, Y., Gao, Z., Liu., D.: Linkage between passenger demand and surrounding land-use patterns at urban rail transit stations: a canonical correlation analysis method and case study in Chongqing. Int. J. Transp. Sci. Technol. 5(1), 10-16 (2016). doi:https://doi.org/10.1016/j.ijtst.2016.06.002

Messenger, T., Ewing, R.: Transit-oriented development in the sun belt. Transp. Res. Rec. 1552(1), 145153 (1996)

Rahman, S., Balijepalli, C.: Understanding the determinants of demand for public transport: evidence from suburban rail operations in five divisions of Indian Railways. Transp. Policy 48, 13-22 (2016). https://doi.org/10.1016/j.tranpol.2016.02.006

Sohn, K., Shim, H.: Factors generating boardings at Metro stations in the Seoul metropolitan area. Cities 27(5), 358-368 (2010). https://doi.org/10.1016/j.cities.2010.05.001

Taylor, B.D., Fink, C.N.Y.: Explaining transit ridership: what has the evidence shown? Transp. Lett. 5(1), 15-26 (2013)

Taylor, B.D., Miller, D., Iseki, H., Fink, C.: Nature and/or nurture? Analyzing the determinants of transit ridership across US urbanized areas. Transp. Res. A Policy Pract. 43(1), 60-77 (2009). https://doi.org/ 10.1016/j.tra.2008.06.007

Wang, F., Antipova, A., Porta, S.: Street centrality and land use intensity in Baton Rouge, Louisiana. J. Transp. Geograp. 19, 285-293 (2011). https://doi.org/10.1016/j.jtrangeo.2010.01.004

Wang, J., Huang, J., Du, F.: Estimating spatial patterns of commute mode preference in Beijing. Reg. Stud. Reg. Sci. 7(1), 382-386 (2020)

Zhao, J., Deng, W., Song, Y., Zhu, Y.: What influences Metro station ridership in China? Insights from Nanjing. Cities 35, 114-124 (2013). https://doi.org/10.1016/j.cities.2013.07.002

Zhong, C., Batty, M., Manley, E., Wang, J., Wang, Z., Chen, F., Schmitt, G.: Variability in regularity: Mining temporal mobility patterns in London, Singapore and Beijing using smart-card data. PLoS ONE, 11(2), e0149222 (2016).

Zhu, Y., Chen, F., Wang, Z., Deng, J.: Spatio-temporal analysis of rail station ridership determinants in the built environment. Transportation 46(6), 2269-2289 (2018)

Publisher's Note Springer Nature remains neutral with regard to jurisdictional claims in published maps and institutional affiliations. 